program. Saturday Skills Courses, Sunday Symposia, Lunch Tickets and Social Program fees are not eligible for this discount.)

\begin{abstract}
ALL ACCESS tickets for Saturday and Sunday Symposia

When you purchase a Saturday course or Sunday symposia, you will be able to access ALL courses or symposium taking place on that day. ALL ACCESS tickets are per day and you must select a main course/symposium for each day. Course books will be distributed for main course/symposia only, additional books will be available for purchase onsite.
\end{abstract}

Registration and Housing for the Annual Meeting will open in December. For more information, please visit www.aats. org/annualmeeting

\section{AATS Aortic Symposium 2014 Call for Abstracts}

\author{
April 24-25, 2014 \\ New York Hilton Midtown \\ New York, NY, USA \\ Course Directors: \\ Steven L. Lansman \\ Westchester Medical Center \\ New York, NY, USA \\ Joseph S. Coselli \\ Baylor College of Medicine \\ Houston, TX, USA
}

AATS AORTIC SYMPOSIUM 2014

AATS AORTIC SYMPOSIUM 2014 is a two-day symposium focused on the pathophysiology, diagnosis and treatment of aortic aneurysms and dissections. This conference is designed for cardiovascular and thoracic surgeons, residents, perfusionists, ICU and OR nurses and those involved with the care of individuals with aortic disease. The faculty consists of world leaders in this field who have been invited to share their experience regarding difficult problems in aortic disease.

Investigators are invited to submit original work to include BOTH of the following:

- Abstract (maximum of 200 words), accompanied by

- PowerPoint presentation of the material (maximum of 12 slides)

\section{OR}

- Abstract (maximum of 200 words), accompanied by

- Video (maximum of 5 minutes, for the Presentation On Demand (POD) system ONLY and must be narrated in English)
AATS Aortic Symposium 2014 will primarily feature faculty presentations of original work or "state-of-the-art reviews." Manuscripts selected from submitted abstracts will comprise the balance of the program and be considered for publication in a supplement of the Journal of Thoracic and Cardiovascular Surgery.

Accepted presentations will be available on the Presentation on Demand (POD) system, a network of computer stations distributed throughout the meeting area that permits attendees to review PowerPoint presentations and videos on demand.

Abstract Deadline: Friday, December 13, 2013, 11:59 PM EST

To submit your abstract, visit www.aats.org/aortic

Authors submitting abstracts for the AATS Aortic Symposium 2014 must use electronic submission ONLY. Visit the AATS Aortic Symposium 2014 Web site at www.aats.org/aortic and select the Submit Abstract link. Specific instructions for abstract submission are located on the Web site, including how to submit graphs or charts.

The American Association for Thoracic Surgery is accredited by the Accreditation Council for Continuing Medical Education to provide continuing medical education for physicians.

This activity has been approved for AMA PRA Category 1 Credits $^{\mathrm{TM}}$.

\section{AATS Leadership Academy}

Friday, April 25, 2014, Toronto, Canada

(Held immediately prior to AATS Annual Meeting)

\section{Applications Now Available: November 30th Deadline}

The 2014 AATS Leadership Academy is an intensive, didactic, and interactive program for up to 20 surgeons who have concluded their residency and been in an academic appointment for no more than three years or will be finishing their residency in 2014 and starting an academic appointment upon its conclusion. Interested applicants should meet the following qualifications:

- Active North American surgeon

- Completed residency and been in an academic appointment for no more than three years or will be completing residency in 2014 and starting an academic appointment upon its conclusion.

- Evidence of academic and leadership accomplishments. 